\title{
Acúmulo e liberação de P, K, Ca e Mg em crotalária e milheto solteiros e consorciados
}

\author{
Adriano Perin ${ }^{1}$, Ricardo Henrique Silva Santos ${ }^{2}$, Segundo Sacramento Urquiaga Caballero ${ }^{3}$, \\ José Guilherme Marinho Guerra ${ }^{3}$, Luiz Antônio Gusmão ${ }^{4}$
}

\begin{abstract}
RESUMO
As características das leguminosas e gramíneas usadas como plantas de cobertura são bastante conhecidas, mas a velocidade com que os nutrientes associados à biomassa vegetal tornam-se disponíveis às culturas é ainda pouco estudada. O objetivo deste trabalho foi determinar o acúmulo e a taxa de liberação de nutrientes de crotalária e milheto solteiros ou consorciados. O delineamento experimental adotado foi blocos ao acaso, com quatro repetições. Os tratamentos foram crotalária, milheto, crotalária + milheto e vegetação espontânea. O acúmulo de P e Mg foi influenciado pela produção de massa, com valores elevados na crotalária, enquanto o acúmulo de Ca resultou tanto do maior teor quanto da maior produção de massa nos tratamentos com a leguminosa. A liberação de nutrientes dos resíduos apresentou dinâmica semelhante, com duas fases distintas: a primeira com taxas mais elevadas nos primeiros 15 dias e a segunda mais lenta a partir dessa fase. As taxas de liberação de K, Ca e Mg foram semelhantes, independentemente dos tratamentos. Os resíduos da crotalária apresentaram maior liberação de $\mathrm{P}$ do que as da vegetação espontânea, com meia vida de 11 dias e a vegetação espontânea de 17 dias. O Ca foi liberado mais lentamente do que os demais nutrientes, e o Mg mais rapidamente. As plantas espontâneas e o milheto apresentam importante potencial na reciclagem de K, e a crotalária se destacou na reciclagem de Ca e Mg.
\end{abstract}

Palavras-Chave: Adubação verde, reciclagem de nutrientes, Crotalaria juncea L., Pennisetum americanum L.

\section{ABSTRACT}

\section{P, K, Ca and Mg accumulation and release by sunnhemp and millet in monocrop and intercropping}

The characteristics of legumes and grasses used as cover crops are well known, but the release rate of nutrients associated with plant biomass becomes available to crops is still little studied. The objective of this work was to quantify the nutrient accumulation and release of sunnhemp and millet in monocrop and intercropping. The experimental design was a randomized complete block with four replicates. The treatments were sunnhemp, millet, sunnhemp + millet and weeds. The accumulation of $\mathrm{P}$ and $\mathrm{Mg}$ was strongly influenced by the dry matter yield, reaching high values in the presence of sunnhemp, while the accumulation of Ca was a result of both the high content and the high dry mater yield in the treatments with the leguminous. The rate of nutrient release showed similar dynamics, with two distinct phases: the first with higher release, in first the 15 days and the second, slowest, from this phase. The intercropping did not affect the release rates of $\mathrm{K}, \mathrm{Ca}$ and $\mathrm{Mg}$, while the presence of sunnhemp enhanced the release of N. Sunnhemp

\footnotetext{
Recebido para publicação em agosto de 2008 e aprovado em março de 2010

${ }^{1}$ Licenciado em Ciências Agrícolas, Doutor. Instituto Federal de Educação, Ciência e Tecnologia Goiano, Campus de Rio Verde, Rodovia Sul Goiana km 01, 75901-970, Rio Verde, GO, Brasil. perinrj@yahoo.com.br.

${ }^{2}$ Engenheiro-Agrônomo, Doutor. Universidade Federal de Viçosa, Av. Peter Henry Rolfs. s/n, 36570-000, Viçosa, MG, Brasil. rasantos@ufv.br.

${ }^{3}$ Engenheiros-Agrônomos, Doutores. EMBRAPA Agrobiologia, CP 74505, 23890-000, Seropédica, RJ, Brasil. urquiaga@cnpab.embrapa.br; gmguerra@cnpab.embrapa.br.

${ }^{4}$ Engenheiro-Agrônomo, Mestre. Instituto do Homem e do Meio Ambiente da Amazônia, Rua Domingos Marreiros, 2020, Fátima, 66060-160, Belém, PA, Brasil. imazon@imazon.org.br.
} 
residues showed a P release higher than weeds, where the sunnhemp T 1/2 was of 11 days and the weeds of 17 days. Ca was released from de mass in a slower rate than the other nutrients, whereas the $\mathrm{Mg}$ was released more quickly. Weeds and millet show a high potential of K recycling and sunnhemp has a high potential of Ca and Mg recycling.

Key words: Green manure, nutrient recycling, Crotalaria juncea L., Pennisetum americanum L.

\section{INTRODUÇÃO}

Diversos fatores estão relacionados com a decomposição e liberação de nutrientes dos resíduos vegetais, como a atuação de macro e microrganismos decompositores, as características químicas do material, o manejo e as condições edafoclimáticas da região ( $\mathrm{pH}$, nutrientes, temperatura e umidade do solo). Nas mesmas condições de clima, solo e manejo, a taxa de decomposição e liberação de nutrientes é influenciada por características químicas inerentes ao resíduo vegetal. Roman \& Veloso (1993) destacam que a temperatura, aerobiose, umidade e o $\mathrm{pH}$ do solo, assim como os teores de nutrientes e a relação $\mathrm{C} / \mathrm{N}$ dos resíduos culturais, estão entre os principais fatores que determinam sua taxa de decomposição. Estudos têm demonstrado que as relações $\mathrm{C} / \mathrm{N}$, lignina/ $\mathrm{N}$ e polifenóis/ $\mathrm{N}$ têm influência direta na decomposição dos resíduos vegetais (Heal et al., 1997; Vanlauwe et al.; 1997). De acordo com Torres et al. (2005), a relação C/N é um dos fatores mais importantes na regulação da decomposição dos resíduos, especialmente em sistemas conservacionistas de manejo do solo.

Segundo Wisniewski \& Holtz (1997), cerca de 85\% do $\mathrm{P}$ contido na biomassa de aveia foi mineralizado num período de 179 dias, tornando-se disponível às culturas em sucessão. O K é normalmente o nutriente mais abundante no tecido vegetal, e como ele se apresenta predominantemente na forma iônica $\mathrm{K}^{+}$, a decomposição dos resíduos o libera na sua totalidade rapidamente (Borkert et al., 2003). Assim, pode-se considerar como $100 \%$ a liberação do K proveniente dos resíduos vegetais, porém podem ocorrer perdas por lixiviação quando se trata de solos arenosos (Calonego et al., 2005). Quanto ao Ca e Mg, existem poucos registros na literatura que caracterizam a dinâmica de liberação desses nutrientes pelos resíduos vegetais (Borkert et al., 2003). Já a taxa de liberação de N encontra-se intimamente relacionada à liberação do C, fato pelo qual vários autores constatam que o $\mathrm{N}$ remanescente segue o mesmo comportamento da biomassa remanescente (Amado et al., 2000; Aita et al., 2001; Aita \& Giacomini, 2003). Esse comportamento reforça afirmações de Torres et al. (2005), em que a relação C/N tem grande contribuição na regulação do processo de decomposição da biomassa vegetal.
Várias espécies de plantas são cultivadas para fins de cobertura do solo. Dentre elas destacam-se as pertencentes à família Fabaceae, pois têm como particularidade o fato de formarem associações simbióticas com bactérias fixadoras de $\mathrm{N}_{2}$. Como resultado da simbiose, quantidade expressiva desse nutriente torna-se disponível às culturas após o manejo da leguminosa, o que pode representar contribuições consideráveis à viabilidade econômica e à sustentabilidade dos sistemas de produção (Boddey et al., 1997), por reduzirem a necessidade de N sintético. Outra característica importante nessa família de plantas é a baixa relação $\mathrm{C} / \mathrm{N}$. Esse aspecto, aliado à presença de substâncias solúveis em grande quantidade, facilita a ação de microrganismos na sua decomposição. A rápida decomposição das leguminosas usadas como plantas de cobertura após o manejo tanto pode assegurar adequado suprimento de nutrientes à cultura em sucessão quanto resultar em grandes perdas.

Quanto à conservação do solo, o ideal é o uso de espécies de cobertura que apresentem menor taxa de decomposição, para manter o solo protegido dos agentes erosivos por maior tempo (Bortolini et al., 2000) e promover a imobilização temporária dos nutrientes em sua biomassa (Andreola et al., 2000). Nesse caso, o emprego de gramíneas pode contribuir ao mesmo tempo para a proteção do solo e para a liberação gradativa de nutrientes. Nesse sentido, há necessidade de se encontrar um equilíbrio entre os aspectos de composição, proteção do solo e liberação de nutrientes. Isso poderá ser alcançado mediante o consórcio entre leguminosas e gramíneas como plantas de cobertura. Embora as características dessas famílias de plantas sejam bem conhecidas, a velocidade com que os nutrientes associados à biomassa vegetal tornam-se disponíveis às culturas é ainda pouco estudada. Ademais, há na literatura relatos sobre o consórcio entre gramíneas e leguminosas invernais, mas há carência de informações quanto ao desempenho de espécies leguminosas e gramíneas de verão. Para tanto, o desafio é conhecer as taxas de decomposição dos resíduos e de liberação de nutrientes de leguminosas e gramíneas de verão empregadas como plantas de cobertura em cultivos solteiro e consorciado. Esse conhecimento contribuirá para sincronizar a oferta de nutrientes dessas fontes com 
a demanda das culturas, o que funcionará como ferramenta para o manejo racional das plantas de cobertura.

Este trabalho teve como objetivos determinar o acúmulo e a taxa de liberação de $\mathrm{P}, \mathrm{K}$, Ca e Mg das espécies vegetais utilizadas como cobertura, a crotalária (Crotalaria juncea L.) e o milheto (Pennisetum americanum L.), nos manejos solteiro e consorciado.

\section{MATERIAL E MÉTODOS}

O experimento foi realizado em Viçosa, MG, num Cambissolo hístico (210 $\mathrm{g} \mathrm{kg}^{-1}$ de areia, $300 \mathrm{~g} \mathrm{~kg}^{-1}$ de silte e $490 \mathrm{~g} \mathrm{~kg}^{-1}$ de argila), com as seguintes características químicas (0-20 cm): $\mathrm{pH}$ em água 5,$3 ; \mathrm{Al}^{+3}, 0,4 \mathrm{cmol} / \mathrm{dm}^{3}$; $\mathrm{Ca}^{+2}, 4,3 \mathrm{cmol}_{\mathrm{c}} / \mathrm{dm}^{3} ; \mathrm{Mg}^{+2}, 1,1 \mathrm{cmol} / \mathrm{dm}^{3} ; \mathrm{K}^{+}, 117 \mathrm{mg} / \mathrm{dm}^{3}$; e P disponível, 92,6 mg/ $\mathrm{dm}^{3}$ de solo. Para correção do $\mathrm{Al}^{+3}$, foram aplicados $1.000 \mathrm{~kg} \mathrm{ha}^{-1}$ de calcário dolomítico (PRNT 100\%), de acordo com Alvarez \& Ribeiro (1999), aos 90 dias que antecederam a semeadura das plantas de cobertura, após uma aração e duas gradagens. A precipitação e a temperatura média mensal ocorridas durante a condução da pesquisa encontram-se na Figura 1.

O delineamento experimental adotado foi o de blocos ao acaso, com quatro tratamentos e quatro repetições. Os tratamentos constaram do manejo da crotalária (Crotalaria juncea), milheto (Pennisetum americanum), crotalária + milheto e vegetação espontânea. A vegetação espontânea foi predominada por capim pé-de-galinha (Eleusine indica L.), capim-colchão (Cenchus echinatus L.), carururoxo (Amaranthus hybridus var. paniculatus L.), carururasteiro (Amaranthus deflexus L.), picão-preto (Bidens pilosa L.), botão-de-ouro (Galinsoga quadriradiata) e titirica (Cyperus rotundus L.) O tratamento crotalária + milheto foi estabelecido pela semeadura de 50\%, em massa, da população de cada espécie, sendo a semeadura realizada em linhas alternadas.

As parcelas constaram de uma área de 4 x $12 \mathrm{~m}$, com linhas espaçadas de $25 \mathrm{~cm}$, numa densidade de 40 plantas/m linear. Por ocasião da semeadura (26/09/2001), bactérias da estirpe BR 2001 do gênero Rhizobium da coleção de culturas da Embrapa - Centro Nacional de Pesquisa de Agrobiologia, foram inoculadas nas sementes da crotalária. Não foi realizada adubação de plantio nem cobertura e também não se fez irrigação, devido à condução do experimento ter sido no período chuvoso. Não foram realizadas intervenções no controle de ervas espontâneas, devido ao rápido crescimento das plantas.

No início do florescimento da crotalária e do milheto, ocorrido aos 68 dias após a emergência (DAE), as plantas foram tombadas com rolo faca. As plantas da área de $1 \mathrm{~m}^{2}$ central de cada parcela foram cortadas rente ao solo e pesadas para determinação do rendimento de massa fresca. Retirou-se uma amostra de aproximadamente $250 \mathrm{~g}$ de massa fresca de cada parcela, colocado-a em estufa de ventilação forçada de ar a $65^{\circ} \mathrm{C}$, até atingir massa constante, para quantificar a produção de massa de matéria seca de parte aérea das plantas. Após secagem em estufa, as amostras foram moídas em moinho tipo Willey, sendo os teores de P determinados conforme Braga \& Defelippo (1974). Os teores de K foram obtidos por fotometria de chama e os de Ca e Mg por espectrofotometria de absorção atômica. Os teores de $\mathrm{C}$ e $\mathrm{N}$ foram determinados e discutidos por Perin et al. (2006). Para o N fez-se a soma dos teores de $\mathrm{N}$ orgânico e $\mathrm{N}$ nítrico, determinados segundo métodos descritos em Jackson (1958) e Cataldo et

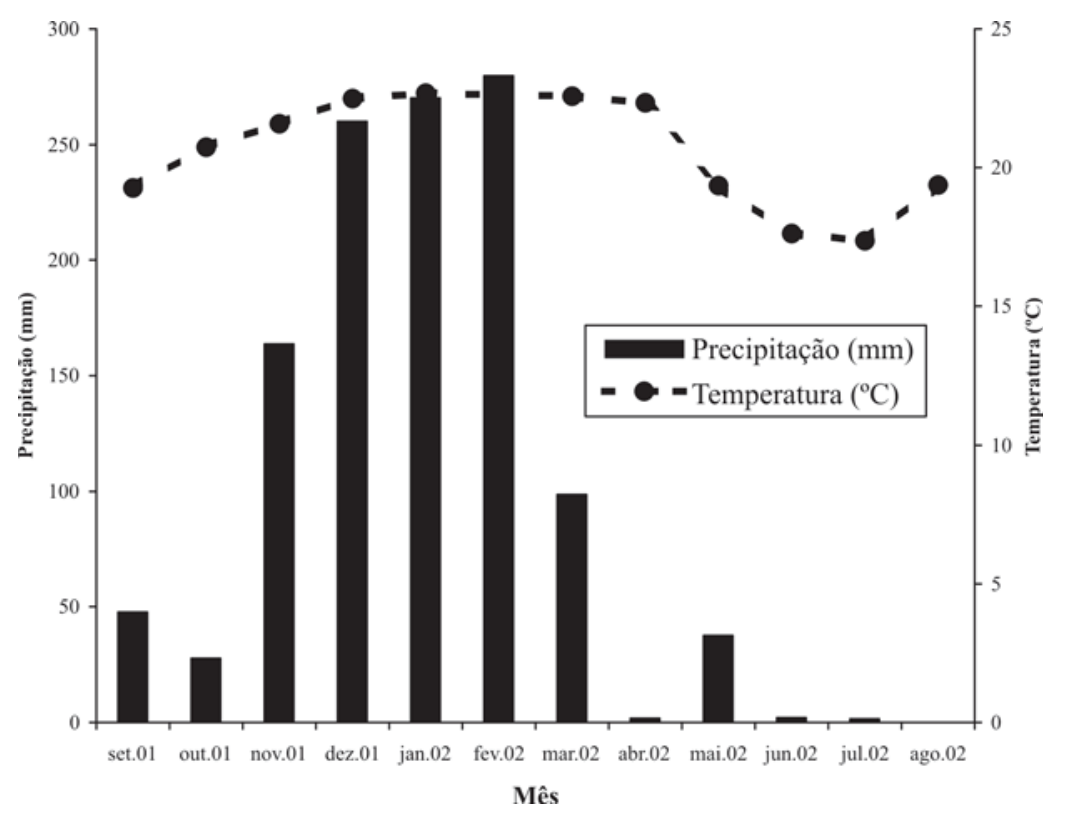

Figura 1. Valores de precipitação e temperatura média da área em estudo durante a condução do experimento. 
al. (1975), respectivamente. A relação C/N será usada no presente estudo como indicadora da taxa de decomposição da biomassa vegetal e sua relação com a mineralização de P, K, Ca e Mg. O acúmulo de nutrientes na massa de matéria seca foi obtido pelo produto da massa de matéria seca pelo teor dos nutrientes.

Por ocasião do corte das plantas, foi instalado o experimento de decomposição in situ com o material fresco da parte aérea das plantas de cobertura, conforme descrito por Resende (2000). De acordo com o método, em cada parcela foram colocadas sete amostras de $100 \mathrm{~g}$ de massa de matéria fresca sobre o solo, cobertas por uma tela de náilon com dimensões de 30 x $30 \mathrm{~cm}$ e abertura de malha de 4 mm. Aos 0, 5, 10, 15, 30, 60, 90 e 120 dias após a instalação do experimento de decomposição, foram coletadas amostras de cada parcela para determinação da massa de matéria seca, seguido de secagem em estufa à temperatura de $65^{\circ} \mathrm{C}$ até atingir massa constante. Posteriormente, as amostras foram moídas para determinação dos teores de P, K, Ca e Mg, conforme método descrito anteriormente. Para a avaliação da dinâmica de decomposição da massa e liberação de nutrientes, foi aplicado o modelo exponencial simples descrito por Thomas \& Asakawa (1993): $\mathrm{Y}=\mathrm{Y}_{0} \mathrm{e}^{-\mathrm{kt}}$, em que $\mathrm{Y}$ é a quantidade de nutriente remanescente após um período de tempo t, em dias, e $\mathrm{Y}_{0}$ é a quantidade de nutriente passível de decomposição no início do ensaio. Segundo esses autores, calculam-se os tempos de meia-vida a partir da equação $\mathrm{T} 1 / 2=\ln { }_{(2)} / \mathrm{k}$, sendo $\mathrm{T}_{1 / 2}$ o tempo necessário para que metade do nutriente seja mineralizado. Os dados relativos à liberação de nutrientes da massa de matéria seca foram submetidos à análise de regressão, enquanto os de acúmulo foram submetidos à análise de variância, adotando-se o teste F, seguido do teste Tukey, ambos a 5\% de probabilidade.

\section{RESULTADOS E DISCUSSÃO}

A crotalária destacou-se na produção de matéria seca por resultar em maior rendimento que a vegetação espontânea, produzindo 9,34 $\mathrm{Mg} \mathrm{ha}^{-1}$ de massa de matéria seca, enquanto o milheto produziu 7,12 $\mathrm{Mg} \mathrm{ha}^{-1}$, o consórcio crotalária + milheto 8,04 Mg ha-1 e a vegetação espontânea 4,49 $\mathrm{Mg} \mathrm{ha}^{-1}$. O rendimento de biomassa dessas plantas de cobertura assemelhou-se ao obtido por outros autores (Ramos et al., 2001; Castro et al., 2004) em condições ambientais similares. É pertinente ressaltar que o consórcio entre crotalária e milheto conferiu menor produção de massa que o cultivo solteiro das espécies.

No consórcio crotalária + milheto, a leguminosa contribuiu com $65 \%$ da produção total de massa de matéria seca. Esse comportamento difere do observado por Heinrichs \& Fancelli (1999), os quais constataram que a aveia (gramínea) confere maior produção de massa quando consorciada com ervilhaca comum (leguminosas). Isso ocorre em especial quando há consórcio entre leguminosas e gramíneas que tenham capacidade de perfilhamento, a exemplo de aveia e azevém. Vale ressaltar que a crotalária e o milheto apresentam hábito de crescimento e porte da planta diferentes do de aveia e ervilhaca comum, sendo esse um fator que pode ter alterado o comportamento dos dados desse experimento quando comparado com Heinrichs \& Fancelli (1999). A menor produção de massa do milheto, no consórcio, pode ser atribuída à competição por recursos naturais, principalmente luz, pois a crotalária apresenta rápido estabelecimento e maior taxa inicial de crescimento, comparativamente ao milheto.

O menor rendimento de matéria seca obtido pelo milheto solteiro comparativamente aos 14,2 $\mathrm{Mg} \mathrm{ha}^{-1}$ obtidos por Oliveira et al. (2002) deve-se, em parte, ao seu menor período de crescimento (68 dias) no presente trabalho, enquanto essa espécie foi amostrada aos 100 dias pelos outros autores (Oliveira et al., 2002). Além disso, as condições climáticas predominantes em cada local influenciam a capacidade de produção de matéria seca. Entretanto, a produção obtida foi superior a $6,0 \mathrm{Mg} \mathrm{ha}^{-1}$, a qual, segundo Darolt (1998), é a quantidade mínima de massa de matéria seca a ser produzida em um sistema de rotação de cultura, para que sejam assegurados os efeitos benéficos da palhada quanto à manutenção e/ou melhoria das características físicas, químicas e biológicas do solo.

Não foram observadas diferenças significativas para os teores de $\mathrm{P}$ e Mg no tecido foliar das plantas de cobertura estudadas, sendo, dessa forma, apresentados os valores médios desses nutrientes. $\mathrm{O}$ teor médio de $\mathrm{P}$ foi 0,37 dag $\mathrm{kg}^{-1}$ e o de Mg 0,62 dag kg-1. No entanto, o acúmulo desses nutrientes foi maior na crotalária quando comparado ao da vegetação espontânea, não diferindo, entretanto, do acumulo do milheto ou do consórcio (Tabela 1). Portanto, o maior acúmulo desses nutrientes na crotalária é resultado de sua maior produção de massa. A crotalária apresentou o maior acúmulo de Ca quando em cultivo solteiro e elevou o acúmulo desse nutriente no cultivo consorciado, comparativamente ao milheto solteiro (Tabela 1). Esse efeito é decorrente tanto da maior produção de massa quanto do maior teor de Ca na crotalária.

Embora as ervas espontâneas tenham apresentado menor produção de massa de matéria seca, elas acumularam quantidades de K similares à da crotalária, do milheto e do consórcio, por causa do seu elevado teor. Assim, as ervas espontâneas presentes na área: capim-pé-de-galinha (Eleusine indica), capim-colchão (Cenchus echinatus), caruru-roxo (Amaranthus hybridus var. paniculatus), caruru-rasteiro (Amaranthus deflexus), picão-preto (Bidens pilosa), botão-de-ouro (Galinsoga quadriradiata) e titirica (Cyperus rotundus) podem promover efeitos de ciclagem de $\mathrm{K}$ similares às espécies empregadas como plantas de cobertura. 
Tabela 1. Acúmulo de nutrientes e relação C/N na parte aérea das plantas de cobertura, aos 68 dias após a semeadura

\begin{tabular}{|c|c|c|c|c|c|}
\hline \multirow[t]{3}{*}{ Sistemas de cultivo } & \multicolumn{4}{|c|}{ Acúmulo de nutrientes } & \multirow{2}{*}{$\begin{array}{c}\text { Relação } \\
\text { C/N(1) }\end{array}$} \\
\hline & $\mathbf{P}$ & $\mathbf{K}$ & $\mathbf{C a}$ & Mg & \\
\hline & \multicolumn{4}{|c|}{ kg ha-1 } & $\%$ \\
\hline Crotalária & 32,48 A & 293,28 A & $90,87 \mathrm{~A}$ & $64,03 \mathrm{~A}$ & 13 \\
\hline Milheto & $28,84 \mathrm{AB}$ & $325,06 \mathrm{~A}$ & 38,37 B & $43,07 \mathrm{AB}$ & 30 \\
\hline Crotalária + milheto & $28,85 \mathrm{AB}$ & $336,80 \mathrm{~A}$ & $64,91 \mathrm{AB}$ & $46,28 \mathrm{AB}$ & 15 \\
\hline Veg. espontânea & $16,84 \mathrm{~B}$ & $277,70 \mathrm{~A}$ & 40,09 B & 27,24 B & 15 \\
\hline C. V (\%) & 26,32 & 26,09 & 36,28 & 28,75 & - \\
\hline
\end{tabular}

* Médias seguidas de letras iguais na coluna não diferem entre si pelo teste de Tukey, a 5\% de probabilidade. DMS para $\mathrm{P}=12,04 ; \mathrm{K}=11,28$; $\mathrm{Ca}=26,98 ;$ e $\mathrm{Mg}=21,10$. ${ }^{(1)}$ Relação $\mathrm{C} / \mathrm{N}$ determinada a partir do trabalho de Perin et al. (2006).

A liberação dos nutrientes P, K, Ca e Mg dos resíduos apresentou dinâmica semelhante, com duas fases distintas (Figuras 2 e 3), com a primeira apresentando taxas mais elevadas nos primeiros 15 dias e a segunda mais lenta a partir dessa data. A rápida taxa inicial de liberação dos macronutrientes está de acordo com outros autores (Da Ros \& Aita, 1996; Rosolem et al., 2003; Crusciol et al., 2005). A semelhança verificada entre os trabalhos quanto à liberação de nutrientes deve-se, em parte, ao fato de os experimentos normalmente padronizarem a floração como a época de manejo das plantas de cobertura. Dessa forma, a composição química da massa das plantas nos diferentes experimentos não se altera substancialmente.

Os resíduos da crotalária apresentaram maior taxa de liberação de $\mathrm{P}$ (Fig. 2a), apresentando $\mathrm{T} 1 / 2$ de 11 dias, enquanto a vegetação espontânea foi de 17 dias (Tabela 2).

Dentre todos os nutrientes estudados, o Ca apresentou menor taxa de liberação, mostrando, dessa for-
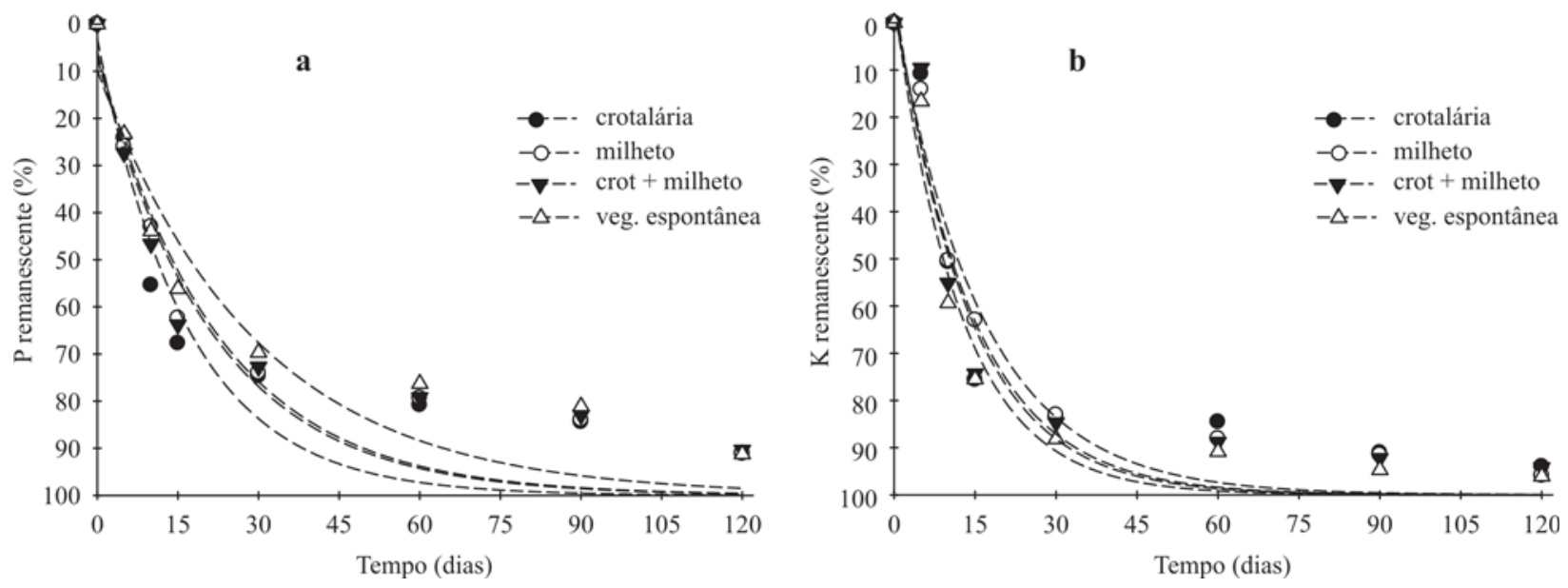

Figura 2. Dinâmica de liberação de P (a) e K (b) das plantas de cobertura entre o período de 5 de dezembro de 2001 a 5 de abril de 2002.
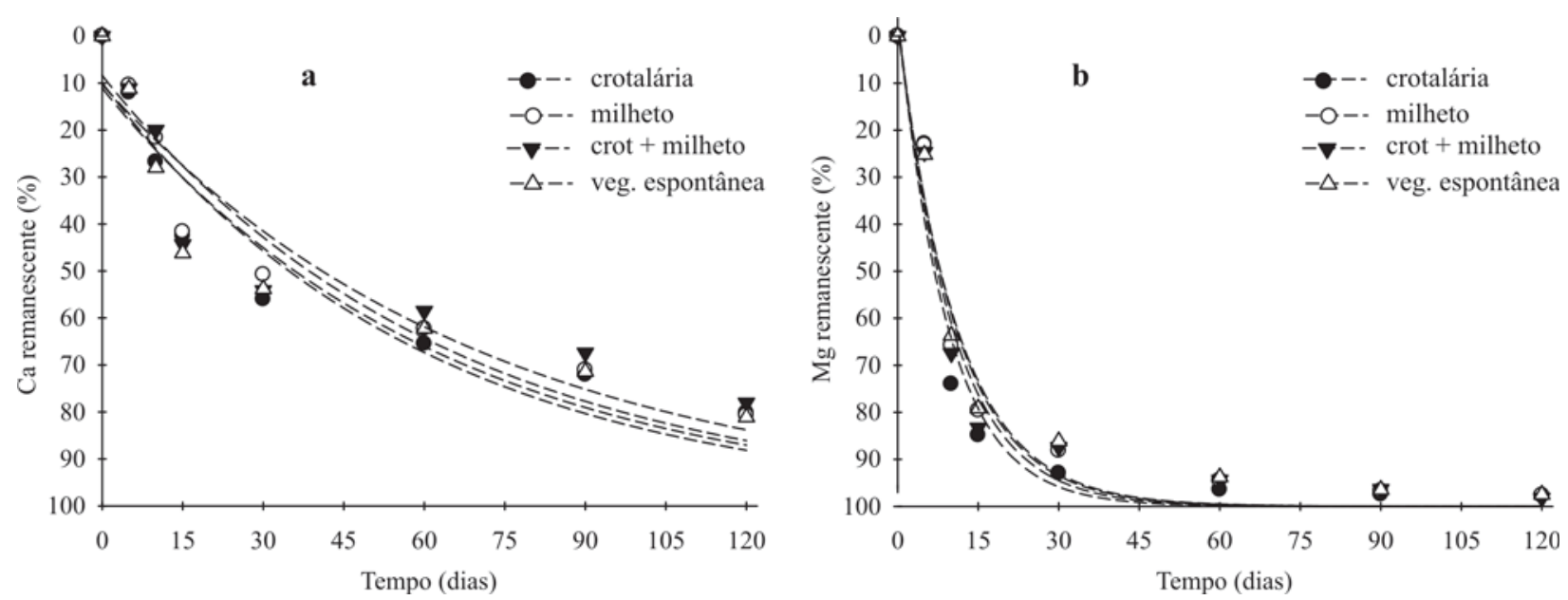

Figura 3. Dinâmica de liberação de Ca (a) e Mg (b) das plantas de cobertura entre o período de 05 de dezembro de 2001 a 05 de abril de 2002.

Rev. Ceres, Viçosa, v. 57, n.2, p. 274-281, mar/abr, 2010 
ma, os maiores valores de $\mathrm{T} 1 \frac{1}{2}$ (Tabela 2). Constatou-se também que não houve diferenças na taxa de liberação de Ca entre as coberturas testadas (Fig. 3a). Outros autores relatam baixa taxa de liberação de Ca em diversas leguminosas tropicais anuais para adubação verde, mesmo em condições de alta temperatura e umidade (Cobo et al., 2002), semelhantes ao do presente experimento. A lenta taxa de liberação de Ca do tecido vegetal é característica intrínseca desse nutriente. O cálcio é um dos nutrientes constituintes da lamela média da parede celular e possui as funções de componente da parede celular e manutenção da estrutura das membranas (Vitti et al., 2006), formando um dos componentes mais recalcitrantes dos tecidos vegetais.

O K foi liberado dos resíduos de forma rápida e similar entre as plantas de cobertura (Fig. 2b). O valor de $\mathrm{T} 1 / 2$ variou de 9 a 12 dias em função das coberturas estudadas (Tabela 2). A rápida velocidade de liberação de $\mathrm{K}$, independentemente da planta de cobertura envolvida, também foi observada por outros autores em condições climáticas semelhantes às do presente experimento (LunaOrea et al., 1996; Calonego et al., 2005; Espindola et al., 2006). O K é o íon mais abundante nas células vegetais (Marschner, 1995), e sua rápida liberação dos resíduos provavelmente está associada ao fato de tal nutriente ocorrer na forma iônica nas plantas, não participando, portanto, das estruturas orgânicas (Taiz \& Zeiger, 1991).
De acordo com Rosolem et al. (2003), a acentuada liberação de K é atribuída à remoção de fração solúvel pela água da chuva e à facilidade de decomposição dessa fração pela população microbiana, mesmo quando os resíduos vegetais permanecem na superfície do solo. Em todos os tratamentos, praticamente todo o $\mathrm{K}$ foi liberado nos primeiros 60 dias. Estudos da decomposição e a concentração de nutrientes na palha de aveia preta ao longo do tempo relatam que, passados 55 dias do corte da cultura, o conteúdo de $\mathrm{K}$ da palha havia diminuído em 92 \% (Cottica et al., 1999). Em resíduos de nabo forrageiro, 99\% do $\mathrm{K}$ foi disponibilizado em até 53 dias após o corte da cultura (Marcon et al., 1999). Por outro lado, Rosolem et al. (2003) constataram que os resíduos do sorgo liberaram K numa intensidade bastante baixa. O mecanismo regulador do processo de liberação de $\mathrm{K}$ é físico (palha seca) e químico (difusão do interior das células mortas até próximo à superfície) (Rosolem et al., 2003). Dessa forma, materiais com alta relação $\mathrm{C} / \mathrm{N}$, a exemplo do sorgo, conferem baixa taxa de liberação desse nutriente, já que de acordo com Torres et al. (2005) esse é um fator que apresenta estreita relação na regulação do processo de decomposição da biomassa vegetal.

As implicações negativas da rápida liberação de K podem ser contornadas pela seleção e pelo manejo das plantas de cobertura. De acordo com Rosolem et al. (2003), espécies com maior proporção de colmos do que folhas apresentam

Tabela 2. Equações das estimativas da liberação de nutrientes com as respectivas constantes de decomposição (k) e tempo de meia vida ( $\mathrm{T}$ 1/2 ), das plantas de cobertura entre o período de 05 de dezembro de 2001 a 05 de abril de 2002

\begin{tabular}{|c|c|c|c|c|}
\hline Sistemas de cultivo & Equação & $\begin{array}{l}\text { Const. de decomp. } \\
\text { (k) }\end{array}$ & $\begin{array}{c}\text { Meia vida } \\
\left.\text { ( } T^{1 / 2}\right)\end{array}$ & $\begin{array}{c}\text { Coef. determ. } \\
\left(\mathbf{r}^{2}\right)\end{array}$ \\
\hline & & $\mathbf{P}(\%)$ & & \\
\hline Crotalária & $\hat{\mathrm{Y}}=97,04 \mathrm{e}^{(-0,0597 \mathrm{X})}$ & 0,0597 & 11 & 0,89 \\
\hline Milheto & $\hat{\mathrm{Y}}=94,22 \mathrm{e}^{(-0,0455 \mathrm{X})}$ & 0,0455 & 14 & 0,90 \\
\hline Crotalária+ milheto & $\hat{\mathrm{Y}}=93,16 \mathrm{e}^{(-0,0466 \mathrm{X})}$ & 0,0466 & 13 & 0,87 \\
\hline \multirow[t]{2}{*}{ Veg. espontânea } & $\hat{\mathrm{Y}}=90,38 \mathrm{e}^{(-0,0344 \mathrm{X})}$ & 0,0344 & 17 & 0,89 \\
\hline & & K (\%) & & \\
\hline Crotalária & $\hat{Y}=105,39 e^{(-0,0701 X)}$ & 0,0701 & 10 & 0,92 \\
\hline Milheto & $\hat{\mathrm{Y}}=102,90 \mathrm{e}^{(-0,0612 \mathrm{X})}$ & 0,0612 & 12 & 0,96 \\
\hline Crotalária+ milheto & $\hat{\mathrm{Y}}=106,00 \mathrm{e}^{(-0,0731 \mathrm{X})}$ & 0,0731 & 10 & 0,93 \\
\hline \multirow[t]{2}{*}{ Veg. espontânea } & $\hat{\mathrm{Y}}=104,68 \mathrm{e}^{(-0,0809 \mathrm{X})}$ & 0,0809 & 09 & 0,96 \\
\hline & & Ca (\%) & & \\
\hline Crotalária & $\hat{\mathrm{Y}}=90,13 \mathrm{e}^{(-0,0169 \mathrm{X})}$ & 0,0169 & 35 & 0,90 \\
\hline Milheto & $\hat{\mathrm{Y}}=91,66 \mathrm{e}^{(-0,0157 \mathrm{X})}$ & 0,0157 & 38 & 0,92 \\
\hline Crotalária+ milheto & $\hat{\mathrm{Y}}=89,73 \mathrm{e}^{(-0,0143 \mathrm{X})}$ & 0,0143 & 41 & 0,88 \\
\hline \multirow[t]{2}{*}{ Veg. espontânea } & $\hat{\mathrm{Y}}=98,00 \mathrm{e}^{(-0,0161 \mathrm{X})}$ & 0,0161 & 36 & 0,87 \\
\hline & & $\operatorname{Mg}(\%)$ & & \\
\hline Crotalária & $\hat{\mathrm{Y}}=104,94 \mathrm{e}^{(-0,1077 \mathrm{X})}$ & 0,1077 & 07 & 0,95 \\
\hline Milheto & $\hat{\mathrm{Y}}=103,57 \mathrm{e}^{(-0,0924 \mathrm{X})}$ & 0,0924 & 08 & 0,96 \\
\hline Crotalária+ milheto & $\hat{\mathrm{Y}}=103,62 \mathrm{e}^{(-0,0979 \mathrm{X})}$ & 0,0979 & 07 & 0,96 \\
\hline Veg. espontânea & $\hat{\mathrm{Y}}=102,65 \mathrm{e}^{(-0,0898 \mathrm{X})}$ & 0,0898 & 08 & 0,97 \\
\hline
\end{tabular}


maior retenção do nutriente, pois as células do colmo encontram-se em um estádio mais avançado de lignificação, dificultando tanto a entrada de água como a saída de K.

No que diz respeito ao aproveitamento de K pelas culturas em sucessão, a taxa diferenciada de liberação entre as plantas de cobertura tem grande importância. Conquanto algumas plantas, como o milheto, o nabo forrageiro, a triticale e a crotalária, o liberam numa intensidade elevada (Rosolem et al.; 2003, Crusciol et al., 2005), outras, porém, como o sorgo, liberam o K numa intensidade bastante baixa (Rosolem et al., 2003). Essas últimas plantas de cobertura poderiam ser empregadas em situações de maior período decorrido entre o manejo das espécies de cobertura e a semeadura da cultura subsequente. As plantas de cobertura disponibilizaram, de imediato (10 dias após o manejo), quantidade superior a $140 \mathrm{~kg} \mathrm{ha}^{-1}$ de $\mathrm{K}$, o que corresponde a mais de $173 \mathrm{~kg} \mathrm{ha}^{-1}$ de $\mathrm{K}_{2} \mathrm{O}$; podendo, portanto, atender à demanda inicial das culturas em sucessão. Nesse mesmo período, cerca de $15 \mathrm{~kg} \mathrm{ha}^{-1}$ de P foram liberados dos tecidos orgânicos, que podem ficar disponíveis tanto para absorção quanto para imobilização em compostos minerais de difícil solubilidade. Com relação à prática da adubação potássica, é importante que se conheça o histórico de manejo das plantas de cobertura, bem como a precipitação pluviométrica ocorrida entre o manejo e a semeadura da cultura subsequente, uma vez que a disponibilidade do $\mathrm{K}$ liberado pelos resíduos depende da espécie e da quantidade de chuva recebida, podendo ser considerável frente às doses de adubo normalmente recomendadas.

A rápida liberação do $\mathrm{Mg}$, com $\mathrm{T}$ 1/2 entre sete e oito dias (Tabela 2), é decorrente, segundo Oliveira et al. (1999), da participação desse elemento em compostos iônicos e moléculas solúveis. A crotalária foi a espécie de cobertura que resultou em maior ciclagem de Ca e Mg. Essa espécie disponibilizou o equivalente a $46 \mathrm{~kg} \mathrm{ha}^{-1}$ de Ca nos primeiros 35 dias e $32 \mathrm{~kg} \mathrm{ha}^{-1}$ de $\mathrm{Mg}$ em apenas sete dias do manejo. Com a rápida decomposição e liberação de nutrientes pelas plantas de cobertura estudadas, é possível inferir que, para maximizar o aproveitamento desses elementos, a implantação da cultura subsequente deve ser realizada com maior antecedência possível após o corte da planta de cobertura.

\section{CONCLUSÕES}

A consorciação do milheto com crotalária não influencia as taxas de liberação de $\mathrm{K}$, Ca e Mg .

Os resíduos da crotalária apresentam maior taxa de liberação de P do que a vegetação espontânea.

A taxa de liberação de Ca é mais lenta que a dos demais nutrientes, enquanto o $\mathrm{Mg}$ é o nutriente liberado mais rapidamente.
As plantas espontâneas apresentam alto teor, acúmulo e rápida liberação de $\mathrm{K}$ de seus resíduos, enquanto a crotalária confere os maiores acúmulos de P, Ca e Mg.

\section{AGRADECIMENTOS}

À Capes, pela concessão da bolsa de Doutorado ao primeiro autor.

\section{REFERÊNCIAS}

Aita C \& Giacomini SJ (2003) Decomposição e liberação de nitrogênio de resíduos culturais de plantas de cobertura de solo solteiras e consorciadas. Revista Brasileira de Ciência do Solo, 27:601612 .

Aita C, Basso CJ, Ceretta CA, Gonçalves CN \& Da Ros CO (2001) Plantas de cobertura de solo como fontes de nitrogênio ao milho. Revista Brasileira de Ciência do Solo, 25:157-165.

Amado TJC, Mielniczuk J \& Fernandes SBV (2000) Leguminosas e adubação mineral como fontes de nitrogênio para o milho em sistemas de preparo do solo. Revista Brasileira de Ciência do Solo, 24:179-189

Alvarez Venegas VH \& Ribeiro AC (1999) Calagem. In: Ribeiro AC, Guimarães PTG \& Alvarez Venegas VH. (Eds.) Recomendações para o uso de corretivos e fertilizantes em Minas Gerais: $5^{\mathrm{a}}$ aproximação. Viçosa, Imprensa Universitária, p.43-60.

Andreola F, Costa LM, Olszevski N \& Jucksch I (2000) A cobertura vegetal de inverno e a adubação orgânica e, ou, mineral influenciando a sucessão feijão/milho. Revista Brasileira de Ciência do Solo, 24:867-874.

Braga JM \& Defelippo BV (1974) Determinação espectrofotométrica de fósforo em extratos de solos e plantas. Revista Ceres, 21:73-85.

Boddey RM, Sá JCDM, Alves BJR \& Urquiaga S (1997) The contribution of biological nitrogen fixation for sustainable agricultural systems in the tropics. Soil Biology and Biochemistry, 29:787-799.

Borkert CM, Gaudêncio CA, Pereira JE, Pereira LR \& Oliveira Junior A (2003) Nutrientes minerais na biomassa da parte aérea em culturas de cobertura do solo. Pesquisa Agropecuária Brasileira, 38:143-153.

Bortolini CG, Silva PR \& Argenta G (2000) Sistemas consorciados de aveia preta e ervilhaca comum como cobertura de solo e seus efeitos na cultura do milho em sucessão. Revista Brasileira de Ciência do Solo, 24:897-903.

Calonego JC, Florini JSS \& Rosolem CA (2005) Lixiviação de potássio da palha de plantas de cobertura em diferentes estádios de senescência após a dessecação química. Revista Brasileira de Ciência do Solo, 29:99-108.

Cataldo DA, Aarón M, Schardem M \& Youngs VL (1975) Rapid colorimetric determination of nitrate in plant tissue by nitrification of salicylic acid. Communications in Soil Science and Plant Analysis, 6:71-81.

Castro CM, Alves BJR, Almeida DL \& Ribeiro RLD (2004) Adubação verde como fonte de nitrogênio para a cultura da berinjela em sistema orgânico. Pesquisa Agropecuária Brasileira, 39:779785.

Cobo JG, Barrios E, Kass DCL \& Thomas RJ (2002) Decomposition and release by green manures in a tropical hillside agroecosystem. Plant and Soil, 240:331-342. 
Cottica RL, Pessoa ACS, Crusciol CAC, Marcon E, Moro E \& Souza MA (1999) Persistência de cobertura morta e liberação de nutrientes de palhada de aveia preta em Latossolo Roxo cultivado com milho em plantio direto. In: $27^{\circ}$ Congresso Brasileiro de Ciência Do Solo, Brasília. Anais, Brasília:Sociedade Brasileira de Ciência do Solo. CD-ROM

Crusciol CAC, Cottica RL, Lima EV, Andreotti M, Moro E \& Marcon E (2005) Persistência de palhada e liberação de nutrientes do nabo forrageiro no plantio direto. Pesquisa Agropecuária Brasileira, 40:161-168.

Da Ros CO \& Aita C (1996) Efeito de espécies de inverno na cobertura do solo e fornecimento de nitrogênio ao milho em plantio direto. Revista Brasileira de Ciência do Solo, 20:135-140.

Darolt MR (1998) Princípios para implantação e manutenção de sistemas. In: Darolt MR (Ed.) Plantio direto: pequena propriedade sustentável. Londrina, Iapar, (Circular, 101). p.16-45.

Espindola JAA, Guerra JGM, Almeida DL, Teixeira MG \& Urquiaga S (2006) Decomposição e liberação de nutrientes acumulados em leguminosas herbáceas perenes consorciadas com bananeira. Revista Brasileira de Ciência do Solo, 30:321-328.

Heal OW, Anderson JM \& Swift MJ (1997) Plant litter quality and decomposition: An historical Overview. In: Gadisch G \& Giller K. (Ed.) Nature: Plant litter quality and decomposition. Wallingford, CAB International. p.3-32.

Heinrichs R \& Fancelli AL (1999) Influência do cultivo consorciado de aveia preta (Avena strigosa schieb.) e ervilhaca comum (Vicia sativa L.) na produção de fitomassa e no aporte de nitrogênio. Scientia Agricola, 56:27-31.

Jackson ML (1958) Nitrogen determinations for soil and plant tissue. In: Jackson ML (Ed.) Soil chemical analysis. Englewood Cliffs, Prentice Hall. p.183-204.

Luna-Orea P, Wagger MG. \& Gumpertz ML (1996) Decomposition and nutrient release dynamics of two tropical legume cover crops. Agronomy Journal, 88:758-764.

Marcon E, Pessoa ACS, Crusciol CAC, Cottica RL, Moro E \& Mânica M (1999) Persistência e liberação de nutrientes de palhada de nabo forrageiro em condições de lavoura. In: $27^{\circ}$ Congresso Brasileiro de Ciência Do Solo, Brasília. Anais, Brasília:Sociedade Brasileira de Ciência do Solo. CD-ROM.

Marschner H (1995) Mineral nutrition of higher plants. London, Academic Press. 889p.

Oliveira MW, Trivelin PCO, Penatti CP \& Piccolo MC (1999) Decomposição de nutrientes da palhada de cana-de-açúcar em campo. Pesquisa Agropecuária Brasileira, 34:2359-2362.
Oliveira TK, Carvalho GJ \& Moraes RNS (2002) Plantas de cobertura e seus efeitos sobre o feijoeiro em plantio direto. Pesquisa Agropecuária Brasileira, 37:1079-1087.

Perin A, Santos RHS, Urquiaga S, Cecon PR, Guerra JGM \& Freitas GB (2006) Sunnhemp and millet as green manure for tropical mayze production. Scientia Agricola, 63:453-459.

Ramos MG, Villatoro MAA, Urquiaga S, Alves BJR \& Boddey RM (2001) Quantification of the contribution of biological nitrogen fixation to tropical green manure crops and the residual benefit to a subsequent maize crop using ${ }^{15} \mathrm{~N}$-isotope techniques. Journal of biotechnology, 91:105-115.

Resende AS (2000) A Fixação biológica de nitrogênio (FBN) como suporte da produtividade e fertilidade nitrogenada dos solos na cultura de cana-de-açúcar: uso de adubos verdes. Dissertação de Mestrado. Universidade Federal Rural do Rio de Janeiro, Seropédica. 123p.

Roman ES \& Velloso JARO (1993) Controle cultural, coberturas mortas e alelopatia em sistemas conservacionistas. In: EMBRAPA Centro Nacional de Pesquisa de Trigo (Passo Fundo, RS). Plantio direto no Brasil. Passo Fundo, Aldeia Norte. p.77-84.

Rosolem CA, Calonego JC \& Foloni JSS (2003) Lixiviação de potássio da palhada de espécies de cobertura de solo de acordo com a quantidade de chuva aplicada. Revista Brasileira de Ciência do Solo, 27:355-362.

Taiz L \& Zeiger E (1991) Plant physiology. Redwood City, Benjamin/Cummings Publishing Company. 565p.

Thomas RJ \& Asakawa NM (1993) Decomposition of leaf litter tropical forage grasses and legumes. Soil Biology and Biochemistry, 25:1351-1361.

Torres JLR, Pereira MG, Andrioli I, Polidoro JC \& Fabian AJ (2005) Decomposição e liberação de nitrogênio de resíduos de plantas de cobertura em um solo de cerrado. Revista Brasileira de Ciência do Solo, 29:609-618.

Vanlauwe B, Diels J, Sanginga N \& Merckx R (1997) Residue quality and decomposition: an unsteady relationship? In: Cadisch G \& Giller KE (Ed.) Driven by nature: plant litter quality and decomposition. Wallingford, CAB International. p.157-166.

Vitti GC, Lima E \& Cicarone F (2006) Cálcio, magnésio e enxofre. In: Fernandes MS (Ed.). Nutrição mineral de plantas. Viçosa, Sociedade Brasileira de Ciência do Solo. p.299-325.

Willey RW (1985) Evaluation and presentation of intercropping advantage. Experimental Agriculture, Cambridge, 21:119-133.

Wisniewski C \& Holtz GP (1997) Decomposição da palhada e liberação de nitrogênio e fósforo numa rotação aveia-soja sob plantio direto. Arquivos de Biologia e Tecnologia, 32:1191-1197. 